\title{
Mechanic and Einergy Analysis of combustion efficiency in a pelletizing furnace
}

http://dx.doi.org/10.1590/0370-44672015690191

\author{
Rafael Simões Vieira de Moura \\ Mestrando \\ Universidade Federal de São João Del Rei - UFSJ \\ Departamento de Ciências Térmicas e dos Fluidos (DCTEF) \\ Programa de Pós-Graduação em Engenharia de \\ Energia (PPGEE - UFSJ) \\ São João Del Rei - Minas Gerais - Brasil \\ rafaelsvm@hotmail.com
}

\section{Maysa Teixeira Resende \\ Mestrando \\ Universidade Federal de São João Del Rei - UFSJ \\ Departamento de Ciências Térmicas e dos Fluidos (DCTEF) \\ Programa de Pós-Graduação em Engenharia de \\ Energia (PPGEE - UFSJ) \\ São João Del Rei - Minas Gerais - Brasil \\ mteixeiraresende@gmail.com \\ José Antônio da Silva \\ Professor Associado \\ Universidade Federal de São João Del Rei - UFS \\ Departamento de Ciências Térmicas e dos Fluidos (DCTEF) \\ Programa de Pós-Graduação em Engenharia de \\ Energia (PPGEE - UFSJ) \\ São João Del Rei - Minas Gerais - Brasil \\ jant@ufsj.edu.br}

\section{Julio Cesar Costa Campos \\ Professor Adjunto \\ Universidade Federal de Viçosa - UFV}

Departamento de Engenharia de Produção e Mecânica

Professor no Programa de Pós-Graduação em

Engenharia de Energia (PPGEE - UFSJ)

Viçosa - Minas Gerais - Brasil

juliomcampos20@gmail.com

\section{Introduction}

Pelletizing is the process of compression molding of a material in the form of pellets. A wide variety of different materials can pass through such a process, including chemical compounds, iron ore, animal feed, among others.

In the case of iron ore, pelletizing in ultrafine particles occurs through heat treatment. This ultra-fine fraction (less than $0.15 \mathrm{~mm}$ ) is found this way in nature or created in the beneficiation process. The pelletizing produces spherical agglomerates of sizes in the

Abstract

The objective of this research is to assess how much the improvement in the combustion reaction efficiency can reduce fuel consumption, maintaining the same thermal energy rate provided by the reaction in a pelletizing furnace.

The furnace for pelletizing iron ore is a complex thermal machine, in terms of energy balance. It contains recirculation fan gases and constant variations in the process, and the variation of a single process variable can influence numerous changes in operating conditions.

This study demonstrated how the main variables related to combustion in the burning zone influence fuel consumption (natural gas) from the furnace of the Usina de Pelotização de Fábrica (owned by VALE S/A), without changing process conditions that affect production quality.

Variables were analyzed regarding the velocity and pressure of the fuel in the burners, the temperature of the combustion air and reactant gases, the conversion rate and the stoichiometric air/fuel ratio of the reaction. For the analysis, actual data of the furnace in operation was used, and for the simulation of chemical reactions, the software Gaseq ${ }^{\circledR}$ was used.

The study showed that the adjustment of combustion reaction stoichiometry provides a reduction of $9.25 \%$ in fuel consumption, representing a savings of US\$2.6 million per year for the company.

keywords: natural gas, cost reduction, flame, stoichiometry, iron ore, Gaseq $q^{\circledR}$.

8 to $18 \mathrm{~mm}$ range, with appropriate characteristics to feed reduction units, such as blast furnaces.

The plant under study has an annual budget of production in the range of 4 million tons of iron ore pellets.

Iron ore pellets, derived from the steps of milling, filtering, mixing and pelletizing while still raw and damp, are thermally processed in mobile grill furnaces (Straight Grate). The induration process of iron ore pellets, fundamental to obtain adequate mechanical strength of the pellets, occurs in the burning zone region in the furnace, and is the process step in which all properties of agglomerates are obtained.

In the cooling chamber, the air, at atmospheric temperature, exchanges heat with the hot pellets coming from the burning zone.

The convective air flow cools down the pellets and follows with an elevated temperature to the combustion chamber, through the recovery duct (down comer), where it reacts with the gas in the combustion reaction. 


\begin{tabular}{|c|c|}
\hline \multicolumn{2}{|c|}{ Symbols } \\
\hline $\begin{array}{l}{[\rho] \text { Specific mass }\left(\mathrm{Kg} / \mathrm{m}^{3}\right)} \\
{[\mu] \text { Dynamic viscosity }\left(\mathrm{N} \cdot \mathrm{s} / \mathrm{m}^{2}\right)} \\
{\left[\mathbf{P}_{1}\right] \text { Inlet pressure }(\mathrm{Pa})} \\
{\left[\mathbf{P}_{2}\right] \text { Output pressure }(\mathrm{Pa})} \\
{[\Delta \mathbf{P}] \text { Pressure differential }(\mathrm{Pa})} \\
{[\dot{\boldsymbol{V}}] \text { Volume }\left(\mathrm{m}^{3}\right)} \\
{[\mathbf{Z}] \text { Compressibility factor }(\text { dimensionless })} \\
{\left[\mathbf{R}_{\mathbf{g}}\right] \text { Molar gas constant }(\mathrm{k} / \mathrm{kmol} . \mathrm{K})} \\
{[\mathbf{T}] \text { Temperature }(\mathrm{K})} \\
{[\mathbf{A}] \text { Area }\left(\mathrm{m}^{2}\right)} \\
{[\mathbf{V}] \text { Volumetric flow }\left(\mathrm{m}^{3} / \mathrm{s}\right)} \\
{\left[\mathbf{v}_{\mathbf{1}}\right] \text { Inlet velocity }(\mathrm{m} / \mathrm{s})} \\
{\left[\mathbf{v}_{2}\right] \text { Output velocity }(\mathrm{m} / \mathrm{s})} \\
{[\mathbf{g}] \text { Gravity acceleration }\left(\mathrm{m} / \mathrm{s}^{2}\right)} \\
{[\mathbf{M a}] \text { Mach number }(\text { dimensionless })} \\
{[\mathbf{R e}] \text { Reynolds coefficient }(\text { dimensionless })}\end{array}$ & $\begin{array}{l}{[\mathbf{D}] \text { Diameter }(\mathrm{m})} \\
{[\mathbf{J}] \text { Quantities of motion ratio (dimensionless) }} \\
{\left[\mathbf{Q}_{\text {jet }}\right] \text { Jet quantity of motion }(\mathrm{Kg} \cdot \mathrm{m} / \mathrm{s})} \\
{\left[\mathbf{Q}_{\text {flow }}\right] \text { Flow quantity of motion }(\mathrm{Kg} \cdot \mathrm{m} / \mathrm{s})} \\
{[\eta] \text { Conversion rate }(\%)} \\
{\left[\mathbf{c}_{\mathrm{g}}\right] \text { Combustion gases specific heat }\left(\mathrm{J} / \mathrm{Kg} \cdot{ }^{\circ} \mathrm{C}\right)} \\
{\left[\mathbf{T}_{\mathrm{g}}\right] \text { Combustion gases temperature }\left({ }^{\circ} \mathrm{C}\right)} \\
{\left[\mathbf{T}_{\text {air }}\right] \text { Inlet air temperature }\left({ }^{\circ} \mathrm{C}\right)} \\
{[\mathbf{L H V}] \text { Lower heating value }\left(\mathrm{KJ} / \mathrm{m}^{3}\right)} \\
{\left[\mathbf{V}_{\mathbf{r}}\right] \text { Reactants volume }\left(\mathrm{m}^{3}\right)} \\
{\left[\mathbf{V}_{\mathrm{p}}\right] \text { Products volume }\left(\mathrm{m}^{3}\right)} \\
{\left[\mathbf{Q}^{3}\right] \text { Thermal power }(\mathrm{J})} \\
{\left[\mathbf{Q}_{\text {actual }}\right] \text { Actual thermal power }(\mathrm{J})} \\
\left.\left[\mathbf{Q}_{\eta=0.90}\right)\right] \text { Thermal power of } 90 \% \text { converted fuel }(\mathrm{J}) \\
{\left[\dot{\mathbf{m}}_{\mathrm{f}}\right] \text { Fuel mass flow }(\mathrm{Kg} / \mathrm{s})} \\
{\left[\mathbf{m}_{\mathrm{g}}\right] \text { Combustion gases mass flow }(\mathrm{Kg} / \mathrm{s})} \\
{\left[\mathbf{m}_{\mathrm{factual})}\right] \text { Fuel actual mass flow }(\mathrm{Kg} / \mathrm{s})} \\
{\left[\dot{\mathbf{m}}_{\mathrm{f}(\eta=0.90)}\right] \text { Fuel } 90 \% \text { converted mass flow }(\mathrm{Kg} / \mathrm{s})}\end{array}$ \\
\hline
\end{tabular}

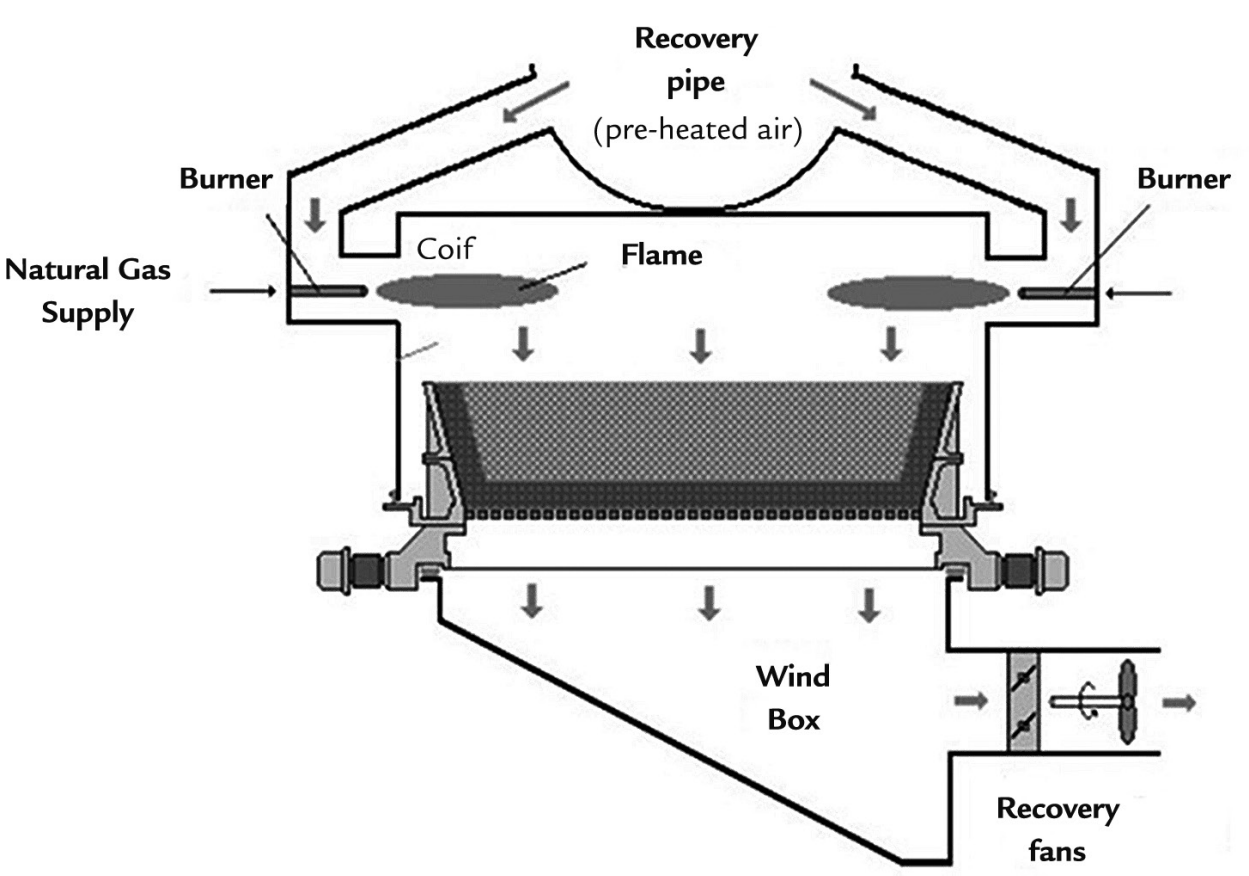

The burning zone, shown in Figure 1 , has the burners where fuel combustion occurs, generating natural gas. The combustion gases are mixed with hot gases that come through the recovery duct from the cooling chamber. This mixture of hot gases permeates the bed of raw pellets brought by grid cars, transferring heat to them. The gases are drawn by a centrifugal fan after passing through the wind boxes, which retains any solid larger mass material, by gravity. Altogether, there are

\section{Materials and methods}

This research included the following variables that affect the energy consumed or given by combustion reaction: the speed and pressure of the fuel in the burner, the temperature of the combustion air and reagent gases, the stoichiometric conversion rate and the air/fuel reaction. As some data is not possible to collect with the furnace in
37 wind boxes in the furnace, connected to the ducts of the fans, that circulating the gases in the furnace. The burning zone is comprised of 12 wind boxes (numbered 12 and 23).

In his work about the global energy balance in the furnace of Usina 1, from CVRD, in Tubarão, Souza and Machado (1975) proposed a thermal efficiency of about $29.18 \%$ for the furnace. The authors emphasize that the energy loss in the burning zone is about $43 \%$ of total heat lost operation, some of these variables were analyzed qualitatively, and proposals have been made for their changes, aimed at reducing fuel consumption.

The operational and constructive data of the iron ore pelletizing furnace used in this study were provided entirely by VALE S/A.
Figure 1

Cross-section of

Burning Zone (Matos, 2007).

from the furnace.

The annual estimated cost for fuel (natural gas) that feeds the furnace of the plant under study is US\$28 million, and is the largest portion of the total production costs, corresponding to $35 \%$.

This study suggests the analysis of the combustion mechanism in the burning zone, more precisely scrutinizing the energy imparted by the combustion reaction, and how this energy can be rationalized to obtain lower fuel consumption.
To simulate the combustion reactions, the Gaseq ${ }^{\circledR}$ software was used. It is a software for chemical equilibrium calculation in combustion reactions, which can be obtained for free. The software has a simple and objective platform, with pre-defined situations of chemical balance and a selection of elements and substances 
that can be selected as reactants and products. The program allows the calculation of incomplete combustion reactions, through the entrance of the concentrations of chemical species, and informs all thermochemical properties of reactants and products involved in the reaction.

It is important to emphasize that the manipulation of process variables in this work, in order to obtain a lower mass flow of fuel, obeyed some important operational criteria, such as maintaining the heat energy rate $(Q)$, since the thermochemical parameters necessary in the process of induration of iron ore pellets should remain unchanged, in order to maintain the quality of production.

Also in relation to the heat energy rate, models in CFD (Computational Fluid Dynamics) as shown in the study by Athayde et al. (2012), demonstrate that it is possible to rationalize the heat transfer between convective flow of combustion gases and the bed of raw pellets in order to maximize power transfer.

Due to the constructive characteristics of the furnace fuel supply system, only the studied fuel in operation was considered; it is natural gas. Therefore, it proved impractical, considering the LHV (Lower Heating Value) from other fuels, which would also lead to variations in the specific heat and temperature of the combustion gases.

\section{Results and discussion}

\subsection{Fuel speed influence}

The fuel required for the combustion reaction in the furnace is injected into the combustion chamber by 38 burners.

Figure 2

Front view of the outlet nozzle of a burner (provided by Vale S/A).

The body of the burner has 1.067 $\mathrm{mm}$ of longitudinal length and $50 \mathrm{~mm}$ of diameter, with $10 \mathrm{~mm}$ thick walls, and has a nozzle formed by 30 or 36 smaller tubes, with $3 \mathrm{~mm}$ of diameter and $10 \mathrm{~mm}$ length each, distributed according to Figure 2.

There is a distribution line of natural gas to the burner, which operates at a pressure of $200 \mathrm{kPa}$.

Through the natural gas composi-

Through transport of fuel in the burner area $(A)$ and the flow rate reading $(\mathrm{V})$ provided by the sensor installed in

This calculation is aimed at obtaining a reference speed in order to determine the type of flow and its influence on combustion. The continuum hypothesis and mass conservation were considered, as well as a flow forced into a duct of constant section without accumulation or mass generation in the fuel injection system.

The Mach number (Ma) relates the speed of a body or stream with the speed

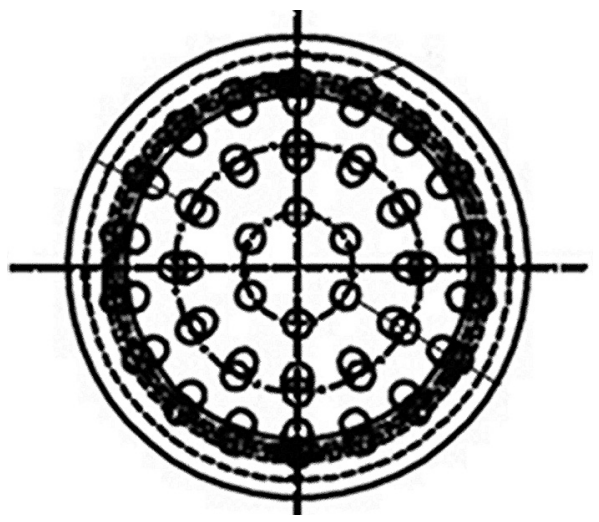

tion provided by the supplier of the fuel dealership, and using Gaseq ${ }^{\circledR}$, it was possible to calculate the density $\left(\rho_{1}\right)$, the dynamic viscosity of the fuel $(\mu)$ and the compressibility coefficient $(Z)$, resulting from the species that make up the fuel. Knowing the inlet pressure $\left(P_{1}\right)$ in the burners and the combustion chamber pressure $\left(P_{2}\right)$ where fuel is injected, we obtain the pressure difference $(\Delta P)$, which

$$
P V=Z R_{g} T
$$

the furnace gas delivery line, the initial speed $\left(v_{1}\right)$ is defined. With this data, was calculated the output speed $\left(v_{2}\right)$, of fuel in

$$
\left.\frac{d m}{d t}\right)=0=\frac{\partial}{\partial t} \int d v+\int(\rho \vec{V} d \vec{A})
$$

of sound in the environment in which it lies. Through the natural gas species composition, its temperature and pressure in the burner, the speed of sound in the flow was obtained, provided by Gaseq ${ }^{\circledR}$. The calculated result for the flow of natural gas was in the order of $\mathrm{Ma}=0.77$. For $0.2<\mathrm{Ma}<0.8$ values, the fluid travels at subsonic speed within the burner showing that there is no temperature elevation or pressure arising comprises the actual pressure drop in the burner, according to the roughness of the building material, turbulence, among others. We considered a Newtonian fluid, in a compressible flow, with a compressibility factor (Z) provided by Gaseq ${ }^{\circledR}$ for adjustment of state equations. The influence of temperature upon density was obtained by Equation 1, whereby the density at the output $\left(\rho_{2}\right)$ was found by Gaseq ${ }^{\circledR}$.

the burner, equal to $332.12 \mathrm{~m} / \mathrm{s}$ through Equation 2, disregarding the terms involving potential energy.

from shock waves (which occur when Ma > 1), which might cause spontaneous ignition in the fuel. The furnace fuel supply system has pneumatic valves that control the flow of fuel in burners, according to the process needs. In the above calculation, these valves were considered fully open, in which the fuel reaches a higher volumetric flow.

In relation to the fuel exit velocity burners, Khalil et al. (2010), in an 
experiment on the temperature distribution in the flame of methane, a major constituent of natural gas, shows that for a pressure of $200 \mathrm{kPa}$, a higher fuel speed

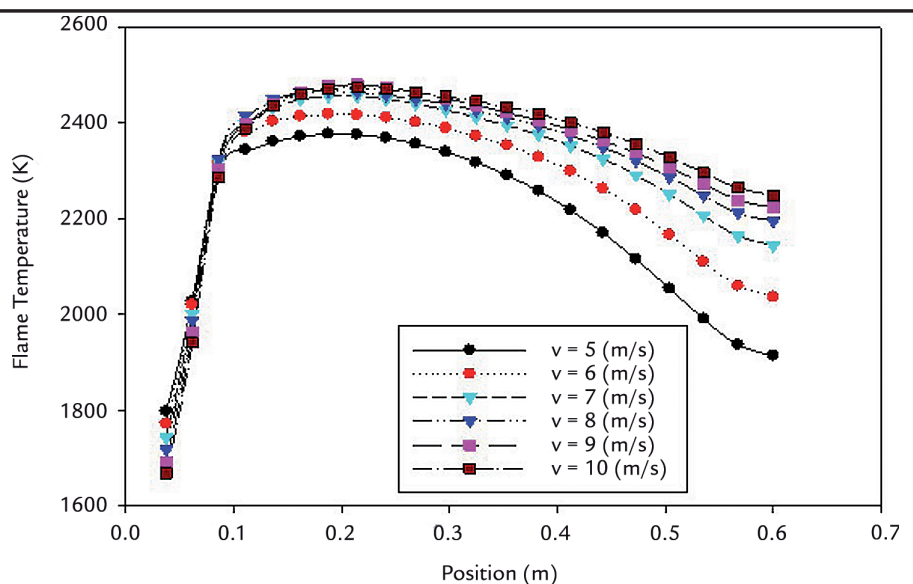

It is noted that the speed of the analyzed gas on the burner favors a more homogeneous temperature distribution

in the flame.

The Gaseq ${ }^{\circledR}$ software reports the values of the dynamic viscosity of the

$$
R e=\frac{\rho v D}{\mu}
$$

features a turbulent flow (Re> 4000).

In turbulent flow conditions in the fuel, flow in the analyzed burner nozzle is on the order of $10^{6}$, shown by Equation 3, which which has a different propagation velocity of provides better energy distribution of the combustion flame (Figure 3).

Figure 3

Flame Temperature

Distribution, ( $\mathrm{P}=2$ (bar) at

Different Velocities). (Khalil et al. 2010).

fuel fluid $(\mu)$ and, along with the value of the output speed $\left(v_{2}\right)$, we calculated the Reynolds number (Re) of the flow.

the flame, a distorted (wrinkled) flame front laminar appears according to the complexity of the velocity field profile as shown in Figure 4.

Figure 4

Sketch of differences in local direction (upper) and flame front topography (lower) between a laminar and turbulent flame (Chatrathi et al., 2001).

Locally, the mixture was further spread with the laminar burning velocity, so the fuel consumption increases proportionally to the surface area increase. The result is equivalent to a faster and more turbulent burning velocity, whose magnitude is related to the intensity of local turbulence and other parameters. The consequence is that the rate of product formation is higher due to the decreased density resulting from the reaction. (Griffiths and Barnard, 1995).

A turbulent flame causes an increase in fuel consumption in the reaction. This effect can be minimized by changing the geometry of the burner, since it becomes impracticable to change the fuel pressure in the supply network, due to the fuel supply project.

In a study on the effects of fuel speeds and flames on burners, Chatrathi et al. (2001), demonstrated that for the relationship between length and tube diameters (L/D) ranging between 1 and 50, the speed is not affected by the diameter, and for ratios exceeding 50, the speed tends to increase proportionally to the diameter. In the case under study, for the burner $(\mathrm{L} / \mathrm{D}=1067 / 40=26.675)$.

Using a simple bench test, it is possible to rationalize the consumption of fuel through changes in the ratio length/ diameter of the burner in study, testing prototypes complying to L/D $<50$ and measuring the mass flow of fuel by correlating data collected by seeking an optimal point of operation. 


\subsection{Fuel pressure influence}

The pressure in the burners study is on the order of $200 \mathrm{kPa}$ in the furnace supply lines. Khalil et al. (2010) in a study

Figure 5

Flame Temperature

Distribution, (Velocity $=10(\mathrm{~m} / \mathrm{s})$, at Different Pressures) (by Khalil, 2010).

The air that enters on the combustion chamber comes from the cooling zone. The load employed in this airflow by the fans causes a cross between the

Figure 6 Jet in cross flow (Lefebvre, 1990 cited by Athayde et al., 2012).

Lefebvre (1990) cited by Athayde et al. (2012), patterned deflection as a func-

where $\mathrm{J}$ is the ratio between the quantities of motion and $\mathrm{Q}_{\text {jet }}$ and $\mathrm{Q}_{\text {flow }}$ represent the quantities of motion of the jet and the gas flow.

Figure 7

Temperature profile along the flame from a burner into the combustion chamber (Athayde et al., 2012). on the influence of pressure variation in flame temperature, illustrates that at different pressures, at the same velocity of fuel, the temperature variation in the flame does not vary in large proportions, as shown in Figure 5. fuel gas stream arising from the burners and the gas flow coming into the combustion chamber.

There is a deflection inside the

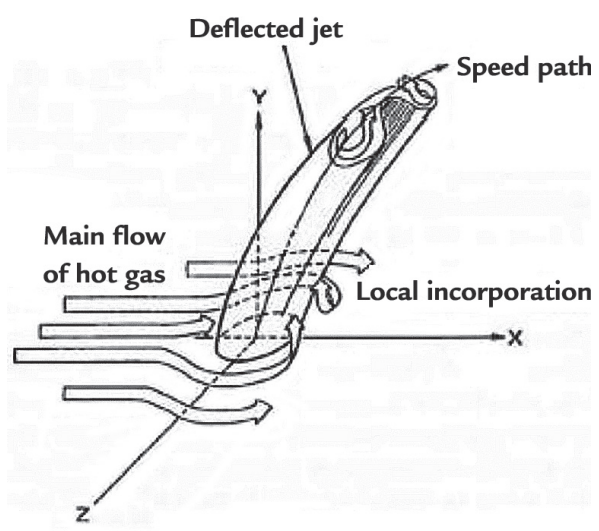

tion of this pressure variation, according to Equation 4.

$$
j=\frac{Q_{\text {jet }}}{Q_{\text {flow }}}
$$

The behavior of the temperature distribution in the flame deflection of a burner from a pelletizing plant furnace similar to that studied in

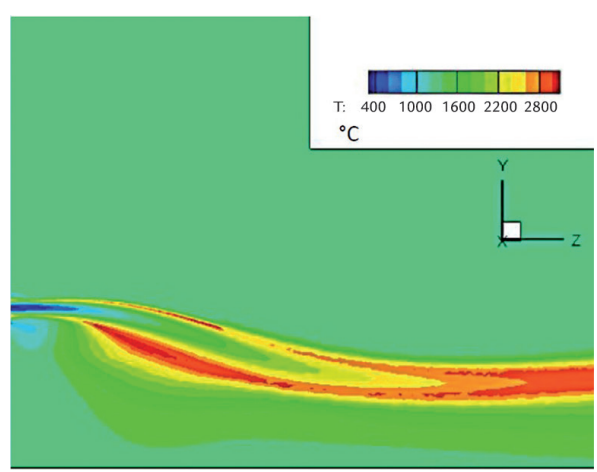

combustion chamber, as shown in Figure 6 , caused by the variation of pressure resulting from a cross between the two flows. this work is illustrated in Figure 7. It was modeled by Athayde et al. (2012) using CFD (Computational Fluid Dynamics). 
In the combustion chamber of the furnace under study, there is a deflection in the flame around an intersection of the flows.

\subsection{Conversion rate influence}

The conversion rate $(\eta)$ of a combustion reaction refers to the conversion percentage of reagents in products, tak-
Reducing the air speed from the cooling chamber will surely result in lower fuel consumption by reducing the deflection in the flame caused

ing as reference the complete combustion stoichiometry, in which $\eta=1$.

The composition of natural gas by the change in pressure from the cross flow, resulting in better flame propagation and consequently better heat transfer.

showed in Table 1 comprises the average of the first five months of 2015 of the gas received from the dealership by VALE S/A.

Natural gas composition

\begin{tabular}{c|c|c|c|c|c|c}
\hline Month & Methane (\%) & Ethane (\%) & Propane (\%) & Butane $+(\%)$ & $\mathrm{N}_{2}+\mathrm{CO}_{2}(\%)$ & $\mathrm{N}_{2}(\%)$ \\
\hline 1 & 88.11 & 6.56 & 2.29 & 0.66 & 2.37 & 0.59 \\
\hline 2 & 88.28 & 6.44 & 2.28 & 0.65 & 2.35 & 0.58 \\
\hline 3 & 88.06 & 6.47 & 2.30 & 0.76 & 2.41 & 0.57 \\
\hline 4 & 88.44 & 6.20 & 2.22 & 0.72 & 2.41 & 0.56 \\
\hline 5 & 88.68 & 6.10 & 2.19 & 0.76 & 2.27 & 0.59 \\
\hline Average & $\mathbf{8 8 . 3 2}$ & $\mathbf{6 . 3 5}$ & $\mathbf{2 . 2 6}$ & $\mathbf{0 . 7 1}$ & $\mathbf{2 . 3 6}$ & $\mathbf{0 . 5 8}$ \\
\hline
\end{tabular}

In this work, there was a comparative study by modeling an equation with a stoichiometric amount of conversion rate $\eta=0.90$. The reactions were simulated in Gaseq $^{\circledR}$ and the temperature of the combustion gas was collected in the software
Table 1

Average of natural gas composition.

for calculating the thermal energy liberated. The stoichiometric balance is shown in Equation 5 below.

$$
\begin{aligned}
& \eta=0.90: \\
& {\left[\mathrm{C}_{1.1064} \mathrm{H}_{4.1656}+0.0178 \mathrm{CO}_{2}+0.0058 \mathrm{~N}_{2}\right]+2.0925^{*}\left(\mathrm{O}_{2}+3.76 \mathrm{~N}_{2}\right) \rightarrow 0.9958 \mathrm{CO}_{2}+0.1106 \mathrm{CO}^{2}+} \\
& +0.0178 \mathrm{CO}_{2}+0.0058 \mathrm{~N}_{2}+2.0828 \mathrm{H}_{2} \mathrm{O}+3.76 * 2.0925^{*} \mathrm{~N}_{2}
\end{aligned}
$$

The Gaseq ${ }^{\circledR}$ software provided all the properties of the reactants and products, necessary for the development of the study.

With the temperature of the

The mass flow of fuel $\left(\dot{m}_{f}=1.741\right.$ $\mathrm{Kg} / \mathrm{s}$ ), for both cases, were considered as the product of the volumetric flow rate of fuel $\left(\dot{V}_{f}=2.318 \mathrm{Nm}^{3} / \mathrm{s}\right)$ measured in the furnace under standard operating conditions and the fuel density $\left(\rho_{f}\right)$ under standard conditions.

The lower heating value $\left(\mathrm{LHV}=36048 \mathrm{~kJ} / \mathrm{m}^{3}\right)$ of natural gas fuel corresponds to an average of 150 days of the reports provided by the concessionaire, considered the same in both cases. The mass flow rate of combustion gas $\left(\dot{m}_{g}\right)$ corresponds to the relative ratio of reactant volumes and product volume $\left(V_{r} / V_{p}\right)$ obtained by Gaseq $^{\circledR}$, the density of reagents $\left(\rho_{\mathrm{r}}\right)$ and the fuel consumption rate $\left(\dot{m}_{f}\right)$. The specific heat of flue gases $\left(C \mathrm{p}_{\mathrm{g}}\right)$ was obtained by Gaseq ${ }^{\circledR}$ for the combustion gases for $\eta=0.90$, and temperatures measured in the furnace burners, it was possible to determine the rate of energy provided by combustion $(\dot{Q})$ in both cases (theo-

$$
\dot{Q}=\dot{m}_{f} L H V-\dot{m}_{g} c P_{g}\left(T_{g}-T_{\text {air }}\right)
$$

species composition in both cases. The variations in the specific heat of flue gases has a direct influence on fuel consumption, since all the energy generated in the combustion reaction depends on the composition of the specific heat of flue gases to be transferred to the bed of raw pellets at a rate more or less effective, depending on its value, Turns (2013) presents a polynomial model to obtain the specific heat in mixtures, that the software Gaseq ${ }^{\circledR}$ simulates with excellent approximation. The gas outlet temperature $\left(T_{\mathrm{g}}\right)$ was obtained by Gase $^{\circledR}$ for $\eta=0.90$ and collected in the field for the real situation. The temperature of the combustion air $\left(\mathrm{T}_{\text {air }}=859^{\circ} \mathrm{C}\right)$ was measured in the furnace and is considered the same retical for $\eta=0.90$ and actual), using Equation 6, which relates the energy released by the fuel with the energy for elevating the temperature of the combustion gases.

for both cases.

For the calculations, the thermal power of combustion in current conditions is $\dot{\mathrm{Q}}_{\text {actual }}=52.018 \mathrm{MJ}$ and $\dot{\mathrm{Q}}_{\eta=0.90}=57.822 \mathrm{MJ}$, therefore a $11.15 \%$ greater heat input by combustion reaction adjustment.

Whereas the maintenance of the same rate of power generation, similar to the current required for induration of the pellets, and adjusting the mass flow of fuel $\left(\dot{m}_{f}\right)$ for the model in which $\dot{\mathrm{Q}}_{\eta=0.90}$, came to a value of $\dot{m}_{f}=1.579$ $\mathrm{Kg} / \mathrm{s}$ for the same furnace operating conditions.

A reduction of $9.25 \%$ in fuel consumption. Table 2 compares the results. 
Table 2

Comparing between

current situation and $\eta=0.90$ for the thermal gains and fuel consumption.

The installation of a combustion gas analyzer on the furnace drawing system is indicated (there are models in the industry

\subsection{Air/fuel ratio influence}

One of the ways to achieve a high conversion rate is through the air/fuel ratio. The fuel has needed to react with the greatest amount mass, possibly oxygen, near the stoichiometric balance of

Table 3

Methane Ignition Temperature for Various Concentrations of Air/Fuel mix.

A low ignition temperature involves a smaller amount of energy given off to perform the reaction, and consequently better utilization of the energy released by the fuel. Thus, excess air can increase the performance of combustion, since it has been analyzed so that the excess air that hangs in the combustion does not absorb

Figure 8 Ratio between the volume of air available, and the volume of fuel into the wind boxes of the combustion region in the furnace.

The result showed that there is excess air volume in relation to fuel volume in the combustion chamber at a different ratio. An analysis of chemical species from combustion gases must be carried out to define the real rate of oxygen that is being

\begin{tabular}{c|c|c|c}
\multicolumn{2}{c|}{ Keeping the fuel consumption $\left(\dot{m}_{c}\right)$} & \multicolumn{2}{c}{ Keeping the thermal power $(\dot{\mathrm{Q}})$} \\
\hline$\dot{\mathrm{Q}}_{\text {actual }}(\mathrm{MJ})$ & $\dot{\mathrm{Q}}_{\eta=0.90}(\mathrm{MJ})$ & $\dot{m}_{\text {factual })}(\mathrm{Kg} / \mathrm{s})$ & $\dot{m}_{f(\eta=0.90)}(\mathrm{Kg} / \mathrm{s})$ \\
\hline 52.018 & 57.822 & 1.741 & 1.579 \\
\hline
\end{tabular}

that analyze the concentration of species $\mathrm{CO}_{x}, \mathrm{NO}_{x}$ and $\left.\mathrm{SO}_{x}\right)$. Through analysis of the species composition of the combustion products, it is possible to adjust the supply of fuel to a better conversion rate $(\eta)$, which can result in $9.25 \%$ consumption reduction. the reaction, to carry out combustion as nearly as possible to be complete. Variations of $20 \%$ surplus air volume in the methane combustion reaction can reduce the ignition temperature of up to $10 \%$. Table 3 shows the relationship between the variation of the air/ fuel ratio and the ignition temperature of methane, the main component of natural gas.

\begin{tabular}{c|c|c} 
Proportion of theoretical air (\%) & $\mathrm{m}_{\text {air }}^{3} / \mathrm{m}^{3}{ }_{\text {methane }}$ & Ignition temperature $\left({ }^{\circ} \mathrm{C}\right)$ \\
\hline 80 & 10.67 & 740 \\
\hline 100 & 9.52 & 705 \\
\hline 110 & 8.00 & 698 \\
\hline 120 & 6.85 & 666 \\
\hline
\end{tabular}

(adapted from Gas Engineers Handbook/ SINDE)

part of the energy released. Vlassov (2001) admits in his work that an excess of $7 \%$ air relative to the volume of fuel in natural gas reactions is ideal, while Bazzo (1995) states that over $12 \%$ would be advisable.

Figure 8 relates the amount of air volume, by the area of each wind box in the burning zone of the furnace, available for combustion reaction with the fuel volume in the same region. Through the fuel flow calculations in the burners and the flow of air from the down comers in the oven under study, it was possible to profile the ratio of the volume of air available in the chamber and the volume of fuel in each wind box in the region of the burners.

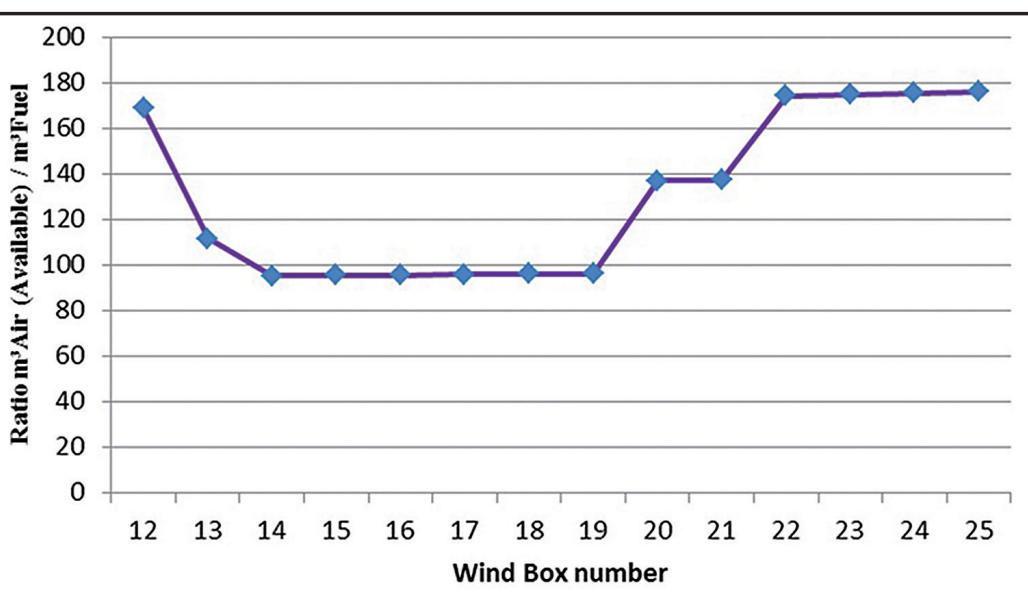

consumed by the fuel. Dadam (2005), in their work, varying the air / fuel ratio in the combustion of natural gas, achieved savings of $48.9 \%$ fuel, only by adjusting the excess air in the reactants.

Through the composition of the chemical species in the products of combustion, it is possible to determine which weight of oxygen was consumed in the combustion reaction, and thus define the actual air/fuel ratio.

The results of this study showed that 
the setting of this parameter tends to significantly reduce fuel consumption in the pelletizing furnace.
It is indicated also for this analysis, the installation of a gas analyzer in the furnace.

Depending on the result of the concen- tration of products, maneuvers in the valves of the fuel supply system can be made to reduce fuel consumption.

\subsection{Combustion air temperature influence}

An important property of the flame temperature analysis is the temperature of the air for combustion (Tair). In his work, Dadam (2005) shows that the higher the temperature of the air reacting with the fuel, the higher is the flame temperature, and hence, higher energy is imparted by the reaction. The air temperature in the furnace combustion chamber is in the order of Tair $=859^{\circ} \mathrm{C}$, which enables a reduction in fuel consumption. However, an analysis of the concentration of the reactants should be performed, monitoring the temperature in the combustion chamber, because high temperatures of combustion air tend to reduce its specific weight, which in a closed system, such as the burning zone, can affect the air/fuel ratio.

\section{Conclusions}

The fuel consumption of a heat engine, the size of a pellet furnace, is linked to structural, thermal, chemical and fluid dynamics factors. The analysis of the combustion performance is just the first step for future studies which should contain the largest possible number of variables in determining the overall efficiency of the system, mainly the burning area, the larger thermal losses region.

For the adjustment of combustion, the installation of a flue gas analyzer in the furnace drawing system is essential.

It was concluded that the adjustment of a stoichiometric conversion rate $\eta=$ 0.90 provides a reduction of $9.25 \%$ in fuel consumption, representing a savings of US\$2.6 million per year for the company.

\section{Acknowledgments}

The authors thank VALE S/A for all the provided information and CAPES for financial support.

\section{References}

ATHAYDE, M., NUNES, S.F., SILVA, G.A.L., SOUSA, F.D.A., ARIMA, M.N., In: INTERNATIONAL CONGRESS ON THE SCIENCE AND TECHNOLOGY OF IRONMAKING, 6 , 2012. Rio de Janeiro: abm, 2012. Novel burner design supported by cfd to minimize deposits inside combustion chambers of samarco pelletizing furnace, p.100-105.

BAZZO, E. Geração de vapor. 2. Ed. Florianópolis: UFSC, 1995. 216 p.

BARATI, M., Dynamic simulation of pellet induration process in straight-grate system. International Journal of Mineral Processing, London, v.89, p.30-39, December 2008.

CHATRATHI, K., GOING, J. E., GRANDESTA, B. Flame propagation in industrial scale piping, Process Safety Progress 286-294. 2001.

DADAM, A. P., Análise térmica de um forno túnel utilizada na indústria de cerâmica vermelha. Florianópolis: Programa de Pós-graduação em Engenharia Mecânica, Universidade Federal de Santa Catarina, 2005. 125 p. (Dissertação de Mestrado em Engenharia Mecânica).

GRIFFITHS, J.F., BARNARD J.A. Flame and Combustion, 3rd Edition. Front Cover. CRC Press, Dec 30, 1995 - Science - 328 p.

KHALIL R.H., SAKHRIEH A., HAMDAN M., ASFAR J. Effect of pressure and inlet velocity on the adiabatic flame. Jordan Journal of Mechanical and Industrial Engineering, v. 4, p.2128, January 2010.

MAJUMDER, S., NATEKAR, P., RUNKANA, V. Virtual indurator: a tool for simulation of induration of wet iron ore pellets on a moving grate, computers and Chemical Engineering, 33, p. 1141-1152, 2009.

MATOS, A.P. Influência da temperatura, pressão, produção e granulometria no processo de secagem das pelotas cruas, Ouro Preto: REDEMAT-UFOP, 2007. 150p. (Dissertação de Mestrado em Engenharia Metalúrgica).

MEYER, K., Pelletizing of Iron Ores. Düsseldorf: Springer-Verlag mbH, 1980. p 205.

MORLEY, C. Developer of software Gaseq ${ }^{\circledR}$, available in <http://www.gaseq.co.uk/> - Accessed in 6/25/2015, 21:30:30.

SOUZA, R.P., MACHADO, A.F. Balanço térmico de um forno de pelotização (Lurgi-Dravo) de minério de ferro hematitico, intern report, CVRD, 1975.

TURNS, Stephen R. Introduction to combustion - concepts and applications. (3.ed.). McGraw-Hill education, 2013.

VLASSOV, D. Combustíveis, combustão e câmaras de combustão. Curitiba: UFPR, 2001, 185 p.

Received: 18 January 2016 - Accepted: 27 April 2016. 